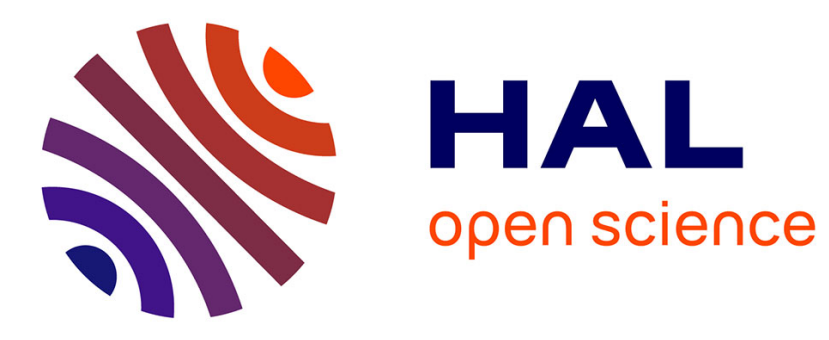

\title{
Wavelet Based Resolution Enhancement for Low Resolution Satellite Images
}

Akansha Garg, Sashi Vardhan Naidu, Hussein Yahia, Darmendra Singh

\section{To cite this version:}

Akansha Garg, Sashi Vardhan Naidu, Hussein Yahia, Darmendra Singh. Wavelet Based Resolution Enhancement for Low Resolution Satellite Images. 9th IEEE International Conference on Industrial and Information Systems (ICIIS2014), IEEE UP Section (India), IEEE MP Subsection, Dec 2014, Gwalior, India. hal-01070357

\section{HAL Id: hal-01070357 https://hal.inria.fr/hal-01070357}

Submitted on 1 Oct 2014

HAL is a multi-disciplinary open access archive for the deposit and dissemination of scientific research documents, whether they are published or not. The documents may come from teaching and research institutions in France or abroad, or from public or private research centers.
L'archive ouverte pluridisciplinaire HAL, est destinée au dépôt et à la diffusion de documents scientifiques de niveau recherche, publiés ou non, émanant des établissements d'enseignement et de recherche français ou étrangers, des laboratoires publics ou privés. 


\section{Wavelet Based Resolution Enhancement for Low Resolution Satellite Images}

\begin{abstract}
Satellite images play a major role in the analysis of land cover, topographic analysis, geosciences etc. There has always existed a tradeoff between the image resolution and the image cost. In this paper, a modified discrete wavelet transform and interpolation based technique is proposed for enhancing the resolution of satellite images having low resolution in such a way that a highly resolved satellite image can be obtained without losing any image information. The advent of DWT has given a major impetus to many techniques based on achieving super resolution starting with a single low resolution image. In the proposed method, DWT is employed on the input satellite image to decompose it into sub-bands then the high frequency subbands and the input low resolution satellite image have been interpolated to obtain four interpolated images which are later combined after minor alterations to the interpolated input image using IDWT. The quantitative peak signal-to-noise ratio (PSNR) and classification results show that the resolution has been enhanced to a good scale without losing any information content present in the satellite image.
\end{abstract}

Keywords-resolution enhancement; satellite images; discrete wavelet transform

\section{INTRODUCTION}

Satellite images are being exploited in many applications where their resolutions play a crucial role which varies depending on the instrument used and the altitude of the satellite's orbit. Satellite data users prefer to receive images with high spatial resolution, but building such a satellite sensor is challenging and costly. In India, the use of satellite data in agriculture is a rapidly emerging and promising trend. Satellite imagery data may facilitate to resolve both major and definite agricultural management tasks such as salinity, land erosion, arable land acreage determination, swamping and desertification assessment, crop condition monitoring, soil composition determination, timely execution and quality monitoring of agricultural measures [1].

Now-a-days, resolution has been referred as a most deciding feature of an image in many image and video processing applications, such as feature extraction [2], video resolution enhancement [3], and satellite image resolution enhancement [4]. Resolution enhancement techniques are basically used as processes that enlarge the given input lowresolution so that the image obtained is sharper. Images having high-resolution are helpful in many fields such as remote sensing, medical diagnostics, military information gathering and video frame freezing etc. However, these high resolution images are difficult to obtain in general cases because of some restrictions of the image sensors and highprecision optics such as their physical capacity and high cost [5]. Therefore, resolution enhancement techniques for lowresolution images came into picture to transform those images into high-resolution ones so that they could be applicable for various applications

Interpolation has been extensively used for resolution improvement $[6,7]$. Normally used interpolation techniques are based on nearest neighbors (include nearest neighbor, bilinear, bicubic, and lanczos interpolations). Resolution improvement schemes (which are not based on wavelets) suffer from the negative aspect of losing high frequency contents i.e. edges (which results in blurring) due to the smoothening caused by interpolation techniques. Therefore recently, wavelets play an important role in enhancing the resolution of low-resolution images without losing edge information [8]. Other applied fields that are taking advantage of wavelets embrace nuclear engineering, astronomy, signal and image processing, sub-band coding, magnetic resonance imaging, fractals, earthquake-prediction and radar etc. Algorithms based on wavelet domain have also been proved successful for various tasks of image resolution enhancement.

Recently, there has been much curiosity in wavelet-based algorithms for image enhancement tasks and several methods have been studied by several researchers $[5,9-15]$ to enhance the sharpness of the reconstructed images by estimating the unknown details of wavelet coefficients. Various resolution enhancement techniques have been developed so far, mainly, for well-known benchmark images like Lena, Baboon etc. But the scenario is somewhat different here while working on satellite images. In case of satellite images, we have to deal with their band values instead of grey scale intensity values like in benchmark images, which itself is a challenging task.

In this paper, we have proposed a modified technique which is based on discrete wavelet transform and interpolation. Our main focus is to enhance the resolution of a low-resolution satellite image (i.e. MODIS with $250 \mathrm{~m}$ resolution) without losing any information contained in it. After obtaining the high-resolution output image, classification results and various quality assessment parameters are used to test this resolution enhancement technique. 


\section{Study AREA AND Data Set Used}

\section{A. Study Area}

The area under study comprises of some regions of Uttar Pradesh and some of Uttarakhand state, India namely it includes the cities of Bijnor, Najibabad, Roorkee, Haridwar, Muzaffarnagar, and Meerut. The area is rich in diverse landscape types such as water, grasses, trees, roads and residential areas, which is desirable for applying the classification test. The region is bounded by latitudes $28^{\circ} 56^{\prime} 7.30^{\prime \prime} \mathrm{N}$ and $29^{\circ} 59^{\prime} 3.59^{\prime \prime} \mathrm{N}$ and longitudes $77^{\circ} 18^{\prime} 39.49^{\prime \prime} \mathrm{E}$ and $78^{\circ} 26^{\prime} 35.09^{\prime \prime} \mathrm{E}$

\section{B. Satellite Data Used}

Moderate Resolution Imaging Spectroradiometer (MODIS), an optical data set is used for study and classification. The MODIS image provides an estimate of the spectral reflectance of the surface. MODIS data is available in different bands with different resolutions. The spectral bands which are used for the study are (i) Red (620-670 nm) and (ii) NIR (Near Infrared) $(841-876 \mathrm{~nm})$ bands with $250 \mathrm{~m}$ resolution. MOD09 Surface Reflectance 8-day L3 global (Data ID: MOD09Q1.A2011097.h24v06.005.2011109183815) data is used which has been acquired on April 19 ${ }^{\text {th }}, 2011$.

\section{THEORETICAL BACKGROUND AND IMPLEMENTATION}

\section{A. Preprocessing of MODIS Images}

The calibrated and geo-referenced MODIS data is directly available, but the products are available in sinusoidal (SIN) projection grid. Therefore, band 1 and band 2 of MODIS are geometrically converted into UTM projection using ENVI4.8 software. An important problem in the use of optical images is occurrence of clouds. The land surfaces of those areas can be seen only which are not affected by the presence of clouds. The preprocessed MODIS data consists of two bands one in the near infrared (NIR) and other is red wavelength. These two bands may be fused or processed individually as per the application [16].

\section{B. Vegetation Parameter}

Surafce reflectances at two or more wavelengths are combined to produce vegetation indices (VIs) which are designed to emphasize a particular feature of vegetation. There are quite a lot of vegetation indices published in the scientific literature, each accentuates a particular vegetation property. ENVI4.8 is used to calculate the NDVI values of the image. NDVI is used to analyze the vegetation cover over a region.

The Normalized Difference Vegetation Index (NDVI) is mainly used to characterize the vegetation regions, as it is almost linearly associated to the vegetation abundance. NDVI is defined as the ratio of the difference and sum of the spectral response at the near infrared (NIR) wavelength and red wavelength as [17]

$$
N D V I=\frac{\rho_{N I R}-\rho_{R E D}}{\rho_{N I R}+\rho_{R E D}}
$$

where $\rho_{N I R}$ and $\rho_{R E D}$ are the reflectances at NIR band and RED band respectively.

Possibly, NDVI values lies between -1 and 1 . While considering the vegetation, the NDVI values are found to lie in the range of 0.1 to 0.6 , where the lower values point toward the lower density and the higher values signify the higher density as more abundance of the vegetation. The values around zero refer to the presence of the soil and rock whereas the negative values of the NDVI characterize the water bodies. NDVI values saturates approximately at 0.6 which usually occurs in case of dense forest area.

\section{Proposed Resolution Enhancement Technique}

Image interpolations based resolution enhancement increases the number of pixels in the image, there are primarily three main techniques i.e. nearest neighbor interpolation, bilinear interpolation and bi-cubic interpolation. The application of these methods results in the softening of edges, creating a blurring effect on the image. The Discrete Wavelet Transform (DWT) based resolution enhancement is a relatively new concept, but it is able to address the problem of blurring. By applying DWT, the low resolution input satellite image is decomposed into four sub-bands, three high frequency sub-bands (LH, HL and $\mathrm{HH}$ ) and the other low frequency sub-band (LL) which is a low resolution approximation of the input image but all the four sub-bands obtained are of half the size of that of the input image. These sub-bands are shown in the Fig. 1 below.

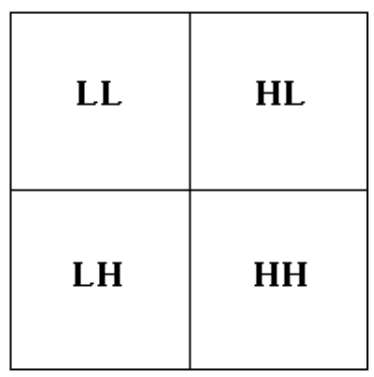

Fig. 1. Four sub-bands obtained by DWT

In this resolution enhancement technique, after applying DWT on the input image using HAAR wavelet function, the high frequency sub-bands i.e. $\mathrm{LH}, \mathrm{HL}$ and $\mathrm{HH}$ are interpolated by a factor of 4 using bicubic interpolation. Haar wavelet is used because it involves less computation. Then the LL sub-band is discarded as it contains less information as compared to the input image. After that, the interpolation of input image is done by a factor of 2 using bicubic interpolation to match its scale with other three high frequency sub-bands, as performed in [18] for well-known standard images like Lena, Elaine, Pepper, and Baboon. However, in case of satellite images, the direct utilization of the input image in place of LL sub-band image causes discrepancies in the pixel values of the final processed image. So while doing exhaustive analysis, it was observed that the errors, which are caused due to alterations to the DWT Image Processing Technique, could be overcome by 
modifying the interpolated input image, via multiplying it by 2 in the proposed technique. Fig. 2 presents the block diagram of the proposed resolution enhancement technique.

The three interpolated high frequency sub-bands and interpolated modified low frequency input image obtained become the High Frequency and LL Sub-bands of the new high resolution image to be obtained.

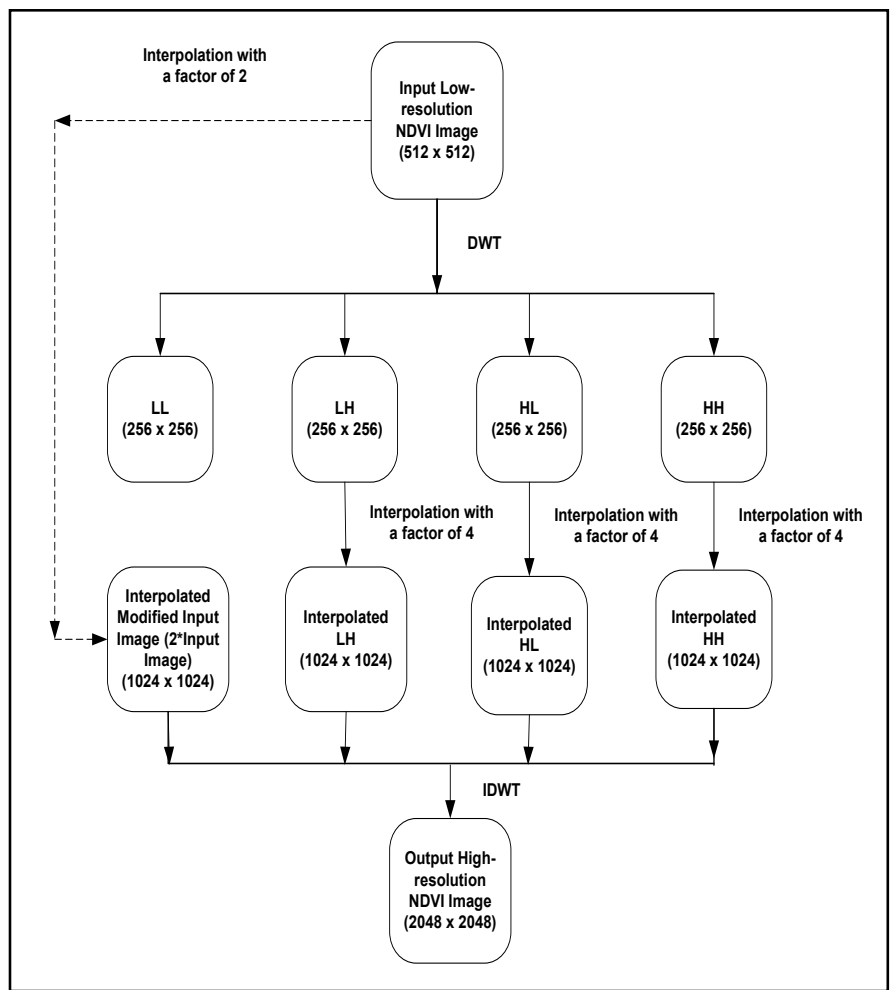

Fig. 2. Block diagram of the proposed resolution enhancement technique

The high Resolution reconstructed image is then obtained after applying IDWT on these four sub-bands. This image offers higher resolution without losing any information content, while preserving the edges present in the input LR image.

\section{Quality Assessment Parameters [19]}

1) Correlation Coefficient: It determines the degree of similarity between two images. The value of the correlation coefficient can be between -1 and 1 . A value of +1 indicates the high degree of correlation between the two images, while a value of -1 indicates that two images are absolutely repugnant to one another. The expression for correlation coefficient is

$$
\operatorname{Corr}(A, B)=\frac{\sum_{j=1}^{n} \sum_{i=1}^{m}\left(x_{i, j}-\mu(A)\right)\left(x_{i, j}^{\prime}-\mu(B)\right)}{\sqrt{\sum_{j=1}^{n} \sum_{i=1}^{m}\left(x_{i, j}-\mu(A)\right)^{2} \sum_{j=1}^{n} \sum_{i=1}^{m}\left(x_{i, j}^{\prime}-\mu(B)\right)^{2}}}
$$

where $\mathrm{A}, \mathrm{B}$ are the input image and the final processed image, $x_{i, j}, x_{i, j}^{\prime}$ are the $(\mathrm{i}, \mathrm{j})$ th pixels of images $\mathrm{A}, \mathrm{B}$ respectively and $\mu(A), \mu(B)$ are the mean values of images A, B respectively.

The greater the value of correlation coefficient, the better preserved is the spectral information content of the original image in the final processed image.

2) RMSE: Root mean square error (RMSE) measures the deviation in the values incurred during the processing of the images. It basically measures the difference in the pixel values of the input low resolution image and output processed image. The expression for RMSE is

$$
\operatorname{RMSE}(A, B)=\sqrt{\frac{\sum_{j=1}^{n} \sum_{i=1}^{m}\left(x_{i, j}-x_{i, j}^{\prime}\right)^{2}}{m^{*} n}}
$$

where $\left(\mathrm{n}^{*} \mathrm{~m}\right)$ are the dimensions of the image.

3) PSNR: Peak signal-to-noise ratio (PSNR) is used to calculate the radiometric distortion of the final image w.r.t the input low resolution image.

$$
P S N R=20 \log _{10} \frac{(\text { Peak })}{M S E}
$$

where

$$
M S E=\frac{1}{N} \sum_{i=1}^{N}\left(H R_{i}-L R_{i}\right)^{2}
$$

where HR, LR and $\mathrm{N}$ represent high resolution image, low resolution image and the number of non-null pixels respectively. The image with high value of PSNR retains the maximum information content from the input image.

\section{RESUlTS AND DisCUSSIONS}

In this paper, a MODIS image of Resolution $512 \times 512$ is enhanced to $2048 \times 2048$ using wavelet transform, implemented in MATLAB. The input low resolution NDVI and the obtained resolution enhanced NDVI images are shown in Fig. 3. Then both of these images are classified using minimum distance classification technique using the software ENVI. The classes considered for classification are water, vegetation and urban. The classified images are displayed in the Fig. 4 where blue, red and green colors represent water, urban and vegetation regions respectively. The user, producer and overall accuracies (in percentage) obtained are mentioned in the Tables 1, 2 and 3. 


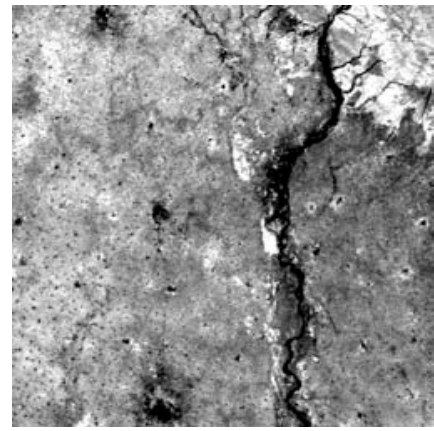

(a)

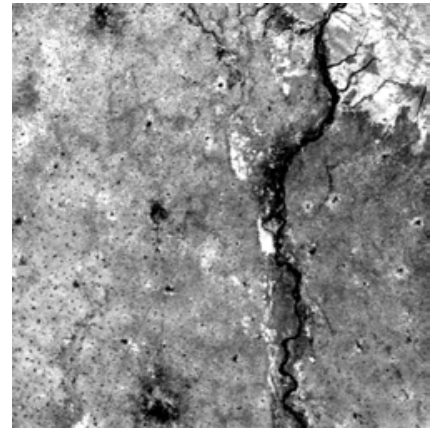

(b)
Fig. 3. (a) Low resolution NDVI image $(512 \times 512)$ (b) Resolution enhanced NDVI image (2048 x 2048)

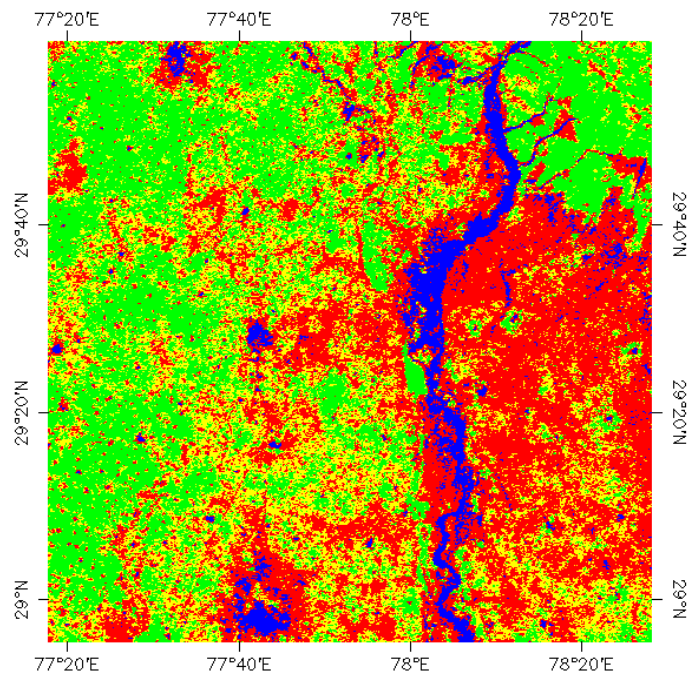

(a)

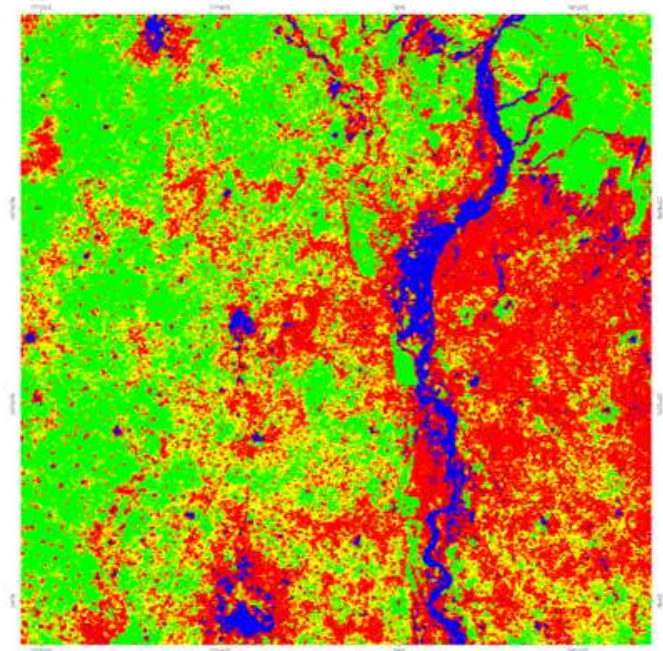

(b)

Fig. 4. (a ) Classified low resolution NDVI image (512 x 512) (b) Classified resolution enhanced NDVI image $(2048 \times 2048)$
TABLE I. USER ACCURACY RESULTS

\begin{tabular}{|c|c|c|}
\hline Classes & $\begin{array}{c}\text { Low Resolution } \\
\text { NDVI Image }\end{array}$ & $\begin{array}{c}\text { Resolution Enhanced } \\
\text { NDVI Image }\end{array}$ \\
\hline Water & 87.58 & 90.63 \\
\hline Urban & 75.00 & 76.67 \\
\hline Vegetation & 96.77 & 89.71 \\
\hline
\end{tabular}

TABLE II. PRODUCER ACCURACY RESULTS

\begin{tabular}{|c|c|c|}
\hline Classes & $\begin{array}{c}\text { Low Resolution } \\
\text { NDVI Image }\end{array}$ & $\begin{array}{c}\text { Resolution Enhanced } \\
\text { NDVI Image }\end{array}$ \\
\hline Water & 94.63 & 95.39 \\
\hline Urban & 76.60 & 77.53 \\
\hline Vegetation & 78.95 & 79.22 \\
\hline
\end{tabular}

TABLE III. OVERALL ACCURACY RESUltS

\begin{tabular}{|c|c|c|}
\hline $\begin{array}{c}\text { Classified } \\
\text { Images }\end{array}$ & $\begin{array}{c}\text { Low Resolution } \\
\text { NDVI Image }\end{array}$ & $\begin{array}{c}\text { Resolution Enhanced } \\
\text { NDVI Image }\end{array}$ \\
\hline $\begin{array}{c}\text { Overall } \\
\text { Accuracy }(\%)\end{array}$ & 85.5799 & 86.4780 \\
\hline
\end{tabular}

The process is able to achieve good enhancement over the direct interpolation techniques such as nearest neighbor, bilinear interpolation, bicubic interpolation etc., which lose a lot of high frequency information. The image was tested with several standard quality assessment parameters like PSNR, RMSE, Correlation Coefficient etc. All of which indicate appreciable results. The values are presented in the Table 4.

TABLE IV. QUALITY ASSESSMENT PARAMETERS

\begin{tabular}{|c|c|c|c|}
\hline Q. A. Parameters & $\begin{array}{c}\text { Correlation } \\
\text { Coefficient }\end{array}$ & RMSE & PSNR (dB) \\
\hline $\begin{array}{c}\text { Resolution Enhanced } \\
\text { NDVI Image }\end{array}$ & 0.9672 & 0.0198 & 31.2598 \\
\hline
\end{tabular}

V. CONCLUSION

In the present work, a modified resolution enhancement technique based on DWT (discrete wavelet transform), has been proposed which opens the prospects of enhancing the quality of a single low resolution MODIS image without the need of any additional images. The freely available MODIS images can be enhanced which serves a lot of applications involving great costs. The proposed algorithm proved successful in providing a resolution enhanced satellite image both quantitatively and visually as PSNR obtained (31.2598 $\mathrm{dB})$ and classification results are quite good which validates that this technique can be used for resolution enhancement of satellite images without losing any image information. Further work is also going on to obtain more enhanced resolution of satellite images.

\section{ACKNOWLEDGMENT}

Authors are thankful to IFCAM for providing the funds to support this work.

\section{REFERENCES}

[1] Available:http://scanex.ru/en/monitoring/default.asp?submenu=farming \&id=index [online]

[2] T. Celik, C. Direkoglu, H. Ozkaramanli, H. Demirel, and M. Uyguroglu, "Region-based super-resolution aided facial feature extraction from low 
resolution video sequences," Proc. IEEE ICASSP, Philadelphia, PA, vol. 2, pp. 789-792, Mar. 2005.

[3] H. Demirel, G. Anbarjafari, and S. Izadpanahi, "Improved motion-based localized super resolution technique using discrete wavelet transform for low resolution video enhancement," Proc. 17th EUSIPCO, Edinburgh, U.K., pp. 1097-1101, Aug. 2009.

[4] H. Demirel and G. Anbarjafari, "Satellite image resolution enhancement using complex wavelet transform," IEEE Geosci. Remote Sens. Lett., vol. 7, no. 1, pp. 123-126, Jan. 2010.

[5] H. Shen, M. K. Ng, P. Li and L. Zhang, "Super-resolution reconstruction algorithm to MODIS remote sensing images", Comput. J., 2007.

[6] Y. Piao, L. Shin, and H. W. Park, "Image resolution enhancement using inter-subband correlation in wavelet domain," Proc. IEEE ICIP, vol. 1, pp. I-445-I-448, 2007.

[7] C. B. Atkins, C. A. Bouman, and J. P. Allebach, "Optimal image scaling using pixel classification," Proc. ICIP, vol. 3, pp. 864-867, Oct. 2001.

[8] S. Mallat, A Wavelet Tour of Signal Processing, 2nd ed. New York: Academic, 1999.

[9] S. Naik and N. Patel, "Single image super-resolution in spatial and wavelet domain," Int. J. of Multimedia \& Its Applications, vol. 5, no. 4 Aug. 2013.

[10] H. Chavez-Roman and V. Ponomaryov, "Super resolution image generation using wavelet domain interpolation with edge extraction via a sparse representation," IEEE Geosci and Remote Sens. Lett., vol. 11, no. 10, Oct. 2014.

[11] W. K. Carey, D. B. Chuang, and S. S. Hemami, "Regularity-preserving image interpolation," IEEE Trans. Image Process., vol. 8, no. 9, pp. 1295-1297, Sep. 1999.
[12] A. Temizel and T. Vlachos, "Wavelet domain image resolution enhancement using cycle-spinning," Electron. Lett., vol. 41, no. 3, pp. 119-121, Feb. 2005

[13] A. Temizel, "Image resolution enhancement using wavelet domain hidden Markov tree and coefficient sign estimation," in Proc. Int. Conf. Image Process., vol. 5, pp. V-381-384, 2007.

[14] H. Demirel and G. Anbarjafari, "Image resolution enhancement by using discrete and stationary wavelet decomposition," IEEE Trans. Image Process, vol. 20, no. 5, pp. 1458-1460, May 2011.

[15] T. Celik and T. Tjahjadi, "Image resolution enhancement using dual-tree complex wavelet transform," IEEE Geosci. Remote Sens. Lett., vol. 7, no. 3, pp. 554-557, Jul. 2010.

[16] T. Ahmed, D. Singh, S. Gupta and R. Balasubramanian, "Particle Swarm Optimization Based Fusion of MODIS and PALSAR Images for Hotspot Detection," Int. Conf. on Microwave and Photonics, Dhanbad, India, Dec. 2013.

[17] R. Prakash, D. Singh, and N. P. Pathak, "A fusion approach to retrieve soil moisture with SAR and optical data," IEEE J. Sel. Topics Appl. Earth Observ. Remote Sens., Sep. 2012.

[18] G. Anbarjafari and H. Demirel, "Image super resolution based on interpolation of wavelet domain high frequency subbands and the spatial domain input image," ETRI J., vol. 32, no. 3, pp. 390-394, Jun. 2010.

[19] G. R. Harish Kumar and D. Singh, "Quality assessment of fused image of MODIS and PALSAR," Progress In Electromagnetics Research B, vol. 24, pp. 191-221, 2010. 